\title{
Re-Viewing Reviews: Scholarship and Translation in India
}

\section{Mahasweta Sengupta}

\begin{abstract}
There has been almost a total saturation in the field of Translation Studies in India during the past decade: everyone seems to be an expert on the very difficult matter of 'Translation' just because they happen to know two languages. It seems to me that there is a need to discriminate between translators who are engaged in the act of translation and scholars who analyse those texts in the larger socio-historical context. While it has been assumed in the Anglo-American world that the translation theorist needs to be a translator first, I think that in India this situation does not work. Here, there has to be a distinction between the two in a large majority of cases because most of these translators are not simply aware of the academic discipline of Comparative Literature which initiated the study of translation as a viable mode of analyzing inter-cultural transfers. This paper proposes to deal with the pathetic situation of Translation Studies in India in spite of the fact that a lot of good translations are being done here at this time. My personal experience of being a student of the discipline of Translation Studies would form the base of this paper.
\end{abstract}

Does a poet need to be a critic or is the critic always a poet? The question takes us to the core of the problem we are trying to negotiate: is a 'translator' a Translation Studies scholar or, is she/he capable of commenting on the academic 'discipline' of Translation Studies? I feel that it is absolutely necessary now to resolve this issue in India, because the act of translation has assumed enormous proportions in the country now and there is a need to decide on what 
is relevant and what is not at this point of time. This is the reason why I consider this occasion to be very important, the question of 'translation-reviewers' is being asked at the right moment when everyone in the country imagines herself or himself to be an expert in translation if she/he happens to know more than one language.

Let me go back to the question with which we started: is the poet a critic, or is a critic necessarily a poet? We know that Rabindranath Tagore or T. S. Eliot wrote both poetry and critical speculations on the nature of poetry; actually, they were masters in both spheres and produced classic material in both. But this fact does not entail that all poets are born critics and therefore they have the power to speculate on the nature of writing. Sometimes, they can talk about their experiences, but that does not make it either theoretically relevant or meaningful. I think there is a need to give the poet the right to exist without asking her/him to be an expert on the art of poetry; she/he does not have to critically comment on the poetry that she/he has written. In fact, we all know how unreliable poets are when they comment on their own work; actually, they maintain a freedom to entertain whatever point of view they think is relevant at the moment. To establish a parallel, I would remind you of Sunil Gangopadhyaya's remark on the translation of his path-breaking Bangla novel where the translator had left out huge chunks because she could not find the right discourse for translating it into English; the writer simply said, she has taken the right decision to edit those parts where she could not find the right English discourse to translate. Here we are speaking of a novel where the language plays a major role; the evolution of language is co-existent with the evolution of the social process and the change of characters. The simple observation that has to be made is that once a text is produced, the writer has no exclusive right over its translation and she/he may choose to say whatever she/he feels like. Remember that rules are proven by exceptions and there would always be some gifted scholars who would be good at both. We are looking at the general situation and not at the exceptions.

As scholars in the area of Translation Studies, we are facing a very complex situation in India. Remember that most of our translators 
are translating into English, and most of them are teachers or students of the 'discipline' of English which has a structure and form since the time it was introduced in India in order to propagate a certain view of the colonizer in the colony. We know that the discipline was initiated here and then transported to England, and there was a specific need for the creation of a canon; a certain ideology was being foisted on the people who learnt the discipline, it was a way in which we moved over to discourses that addressed the western world, in their terms and through their paradigms.

In fact, we are trained by the same system where there has hardly been much change or re-thinking of the critical paradigms that we employ to appraise the discipline. I am certainly not saying that there has not been any change; I am simply saying that change has been slow and rather faltering; you would have a hard time finding scholars who are consciously trying to get out of the ideological binds of English studies in India. What happens in such a situation is evident to all; anyone who knows two languages and is interested in the act of translation thinks that Translation Studies as a discipline is under her/ his expertise; if I am able to translate a text from Telugu into English, I am also capable of commenting critically on the act of translation. In other words, if I can write poetry, I can also be a critic. Actually, you need very different kind of attributes to achieve both.

This is where the problem seeps in. This is the reason why reviews of translated texts are largely comments on the original text; almost all reviewers speak at length on the characters, the plot, the structure and other formal qualities of the original text as if that is what they were asked to review; as Enakshi Chatterjee wrote to me: 'all earlier reviews of my translations were comments on the original novels, as if Tarashankar Banerjee had written the text in English.' How do we make it clear to the reviewers of translated texts that they need to comment on the translation act and not on the original?

I would like to take some time to locate myself at this point. My interest in the discipline of Translation Studies grew from my 
interest in Comparative Literature-not in the sense of 'comparing' two different texts written in two different languages, but in terms of reading literature across national boundaries, beyond limits imposed by narrow national interests. I was always interested in the history of ideas, and my $\mathrm{Ph}$. D. thesis in English was on literary theory of the romantic and modern kind (of the canonical British variety). When I became a student of Comparative Literature in the eighties, I was asked to teach a course in International Short Story to undergraduate students in an American university. I was sure that my syllabus would include stories from India and of course there would be one by Rabindranath Tagore. So I spent days in the library to find a translated short story by Tagore, and failed to find one that would appeal to the students. I was surprised by the very strange translations of the stories that were simply superb in the original; they did not feel the same in the translation. In spite of the difficulties, I did ask the class to read one 'Khokababur Pratyabartan,' the story of a baby being washed away by the mighty river next to his house. The exercise was absolutely unsuccessful; the class hated the story, and I was unable to establish any kind of meaningful relationship between the story and the readers. ${ }^{2}$

This led me to the study of Translation Theory/Studies in detail. I took four three-credit courses on Translation Studies in Comparative Literature, and was exposed to the fascinating world of inter-cultural transfers. Scholars in the discipline of Comparative Literature who were actually interested in Translation Studies that involved an interdisciplinary approach to the topic taught these courses. Remember that this was the time of Post-Saidean historicism in the AngloAmerican academy and inter-cultural transfers exposed fascinating details that were being unearthed for the first time. I worked with the auto-translations of Tagore and came up with a dissertation on the subject. You all know the work of Tejaswini Niranjana who looked into Orientalist translations of Sanskrit texts and exposed how meanings were construed in terms of the demands of the colonizers. There were many others who worked in this fascinating area and produced remarkable readings of translations done between two languages within which the power-relationship played a major role. 
Why am I saying all this? I am trying to aver that being a Translation Studies person involved a disciplinary process; there was a lot to learn and a lot to think about. It is not that we agreed with dominant assumptions of the Anglo-American academy. In fact, I was opposing one basic tenet of western Translation Theory - that the translated text had to fit into the target culture in terms of the demands of that culture. I showed how meanings were altered in such cases to suit the paradigms already prevalent in the target cultures, translators did a great disservice to the density of the original text by conforming to such assumptions. This view was directly in opposition to what Susan Bassnett wrote in her introductory book named Translation Studies published in 1980, where she clearly upheld the view that translation was always determined by target-accessibility and therefore, had to conform to the norms of the target literary system:

To attempt to impose the value-system of SL (source language) culture onto the TL culture is dangerous ground and the translator should not be tempted by the school that pretends to determine the original intentions of an author on the basis of a self-contained text. The translator cannot be the author of the SL text, but as the author of the TL text has a clear moral responsibility to the TL readers. (Bassnett 1980: 23)

Contrary to the Anglo-American view on translation, India has been a multi-lingual habitat, a land where many languages and literatures co-existed for thousands of years. Sanskrit or Arabic-Persian did happen to be the 'Margi' languages, but there were many IndoEuropean or Dravidian or Austro-Asiatic languages which people used in the multi-cultural regions of India. Translation, whenever it occurred, was a re-interpretation of an original: the epics of Ramayana or Mahabharata or mythology of various kinds or indigenous narratives were all translated (or re-written according to Lefevere) in various regional languages and all translators had the freedom to offer a particular reading of the text. This freedom was never questioned think of the rendition of Kasiram Das or Tulasidas - their texts are 
marked by the region they come from. The western notion of 'faithfulness' or 'fidelity' was not a criterion for judging translations in India. It was only accepted as a 'reading' and the translator did not face critics in case he deviated from the original.

Now, since we were picking up the academic discipline of Translation Studies from the West, we did go through the phase of blind imitation. We did expect that target-accessibility was the main marker of success in translation; remember what happened to Edward Fitzgerald's rendition of Omar Khayyam in English-we know that he completely altered the original to fit into the culture of Victorian England. So did Tagore change himself to appear as a mystical, spiritual person to early twentieth-century Englishmen; Yeats thought he experienced a new world through the translated poems of Tagore. In the late nineties, however, we are witnessing the resurgence of a distinct idea that translations have to be read through a set of different terms. Sherry Simon and Matthew St. Pierre's book catches the change in the title of their book, Changing the Terms (1999).

In spite of all these developments, translation-review in India remains a very sad state of affairs. My reading of this situation might sound odd to you, but I cannot restrain myself from sharing my understanding of the confusion in this regard. First, anyone who knows two languages in India assumes that he or she can be a translator. I have met people who are simply devoid of any literary sensibility, who work in government offices that process ration-cards, who studied English in the college or university just because the system demanded a certain amount of knowledge in English. I have received translated texts from the Sahitya Akademi for review, which were translated in the nineteenth century romantic poetic style; on the other hand, I have met people who are seriously interested in the act of translation. Now, it is quite obvious that not everyone would be capable of carrying through the density of the original into English, some of them did not even know why or how they would re-write the original without distorting or editing it in any way. In fact, they did not see any problem whatsoever in editing parts they could not translate-you must have 
seen the size of the translated version of Gora done by various translators and how much they differ in sheer length.

While this is the case with translators, the reviewers do not happen to be any better. I am not suggesting that one or two good translators might appear in this motley crowd; what I am trying to point out is the very heterogeneous nature of the aspirants. Their attitude towards translation is summed up in what P. P. Giridhar said after my paper was read in a conference at Osmania University a few years earlier: 'What we translate has to sound like English, has to look like English. We cannot write something which the Englishaudience would not read.' The question of course is, 'Which Englishaudience and how does one sound like the English?'”

Now the most important question here could be: 'Why do people translate? Or, do they translate for readers who know the original language?' I should admit that this question of Professor Meenakshi Mukherjee ${ }^{4}$ really made me think about all the academic or disciplinary issues about translation. Is a translated text meant for one who can read the text in the original language? I think I reached some sort of an understanding when I realized that this happens to be at the root of the problem we are facing: there should be a distinction between a reviewer (critic) who reads a translated text and explores its characteristics, and a translator who is simply busy with the transfer of meaning. In India, the people who review translations are most of the time simply not aware of the academic discipline of Translation Studies. They do not know what they are supposed to do when they are asked to review a translated text. All their attention therefore goes into the dissection of the characteristics of the original, of analyzing what the original text had to offer. Therefore, the 'reviews' turn out to be not a reading of the translation, but a reading of the original. My understanding is that the lack of scholarship on the discipline is a key factor in the degeneration of the whole practice of 'reviewing' into such a farce. I am sure you understand that I am not suggesting that one has to have a formal degree in Translation Studies; I am hinting that one should at least be familiar with the issues in the discipline to comment on a translated text. 
Let me mention a recent review that I did for Book Review of Aruna Chakrabarti's translation of several Bangla short stories. The book is published by Penguin and the cover tells that the book has been 'edited' by Aruna Chakrabarti. There is no mention of the translator anywhere, but the editor has written a 'Translator's Introduction' where she talks about her experiences in translating and also makes general statements about the discipline. Unfortunately, she is not aware of the developments in the area and her ideas about intercultural transfers are rather naïve to say the least. My reading of this is that she should not have made these general comments without being a student or scholar of Translation Studies and she really sounds very odd in these statements. I reviewed the book in two parts-one dealing with the translations, and one dealing with the Introduction. My instinct tells me that translators should not get into the act of pronouncing judgments on issues in the discipline if they are not familiar with the debates or the arguments prevailing there.

Translation requires a certain kind of a talent and a commitment; you not only know the two languages, but you need to know the two languages sensitively enough to disentangle the ambiguities and the polyvalence of the original and transfer it to the target language as best as possible. You may be an expert in English and you may be a teacher of English, but your skills in the native language are essential for comprehending and translating a text. Naturally enough, it is something more than the mere linguistic ability that is needed-just as a poet you need the power to wield language and manipulate it for constructing the intended meanings. As a critic, you need a different set of qualities-you have to be critically aware of the discourses concerning Translation Studies as a discipline; and in fact, that would be inter-disciplinary and wide-ranging. If you are not a scholar in this area, you should not write REVIEWS of translated texts, because then you will end up summarizing the source text or simply recounting the jargon prevalent in the area. It is high time we realized this and restrained ourselves from commenting on translated texts done by people who naturally need better reviewers for critiquing their work. 
In fact, I think that a great harm is done by commenting not on the translation but on the original by these reviews - they ignore the work done by the translator in rendering a text from one language to another where very important questions regarding inter-cultural transfers are involved. One can only hope to get out of this situation if reviewers acquired or possessed the disciplinary background of Translation Studies.

\section{Notes}

1. In a personal letter to me written after I wrote a review of her translation of Sunil Gangopadhyaya's novel Pradidwandi.

2. International Short Story course at the University of Massachusetts at Amherst, Spring 1986.

3. National Seminar on Translation at Osmania University in 2003. (Since I (=Giridhar) am the person to whom the statement is attributed, I may make the following clarification: Literary translational creativity is all about making the source sensibility wholly, seamlessly and lyrically at home in the target language art. Even with the source sensibility being visibly if seamlessly present in the translation, if it is a creative foreignisation, the translation will sound like being in the target language, and yet have something unjarringly alien in it. An English translation of an Igbo text for instance has to foundationally sound like English even with the Igbo sensibility peeking out of, or standing out in, the other tongue viz English in this case, if you get what I mean. Precisely like what Chinua Achebe did: Igboisation of the English language to the extent technically possible. The qualification is important because the foundational structure of human language (often called 'grammar') has nothing to do with belief systems and cultural ethoses. There can be no denting in the procrustean beds that languages are. Only, in Achebe's case it was not translation. But that is not relevant to the point being made, it seems to me - Editor).

4. In a private conversation about matters of translation.

5. Book Review, New Delhi, January 2007.

\section{Reference}

Bassnett, Susan (1980) Translation Studies, London: Methuen. 